\title{
Technical note: Effects of frozen storage on the mechanical properties of the suspensory tissue in the bovine claw
}

\author{
H. S. Boettcher, ${ }^{\star}$ J. C. Knudsen, † P. H. Andersen, $\ddagger$ and A. M. Danscher $\S^{1}$ \\ *Dyrlægerne Univet, Jernbanegade 10, 6650 Brørup, Denmark \\ †Department of Food Science, University of Copenhagen, Rolighedsvej 30, 1958 Frederiksberg C, Denmark \\ ‡Department of Animal Sciences, Swedish Agricultural University, Box 705475004 Uppsala, Sweden \\ §Department of Large Animal Science, University of Copenhagen, Højbakkegård Allé 5, 2630 Tåstrup, Denmark
}

\begin{abstract}
It is proposed that a softening of the suspensory tissue in the claw is involved in the development of lameness and claw lesions in cattle. A relatively small amount of research has been carried out to verify this theory. Research in this area would be simplified if mechanical testing of the suspensory tissue could be performed on frozen and stored specimens. The current study tested whether freezing of the specimens changes the suspensory tissues' mechanical properties. Limbs from 3 freshly slaughtered Danish Holstein dairy cows and 6 nonpregnant Angus heifers, without clinical signs of lameness, were allocated to 1 of 2 treatments (frozen or nonfrozen) in such a way that each cow was represented in each treatment group with a frozen limb and a corresponding nonfrozen limb (i.e., frozen left front, fresh right front, and so on). The frozen limbs were kept at $-18^{\circ} \mathrm{C}$ for a week before processing and the nonfrozen limbs were processed within $2 \mathrm{~h}$ of slaughter. Two samples measuring $8 \times 8 \mathrm{~mm}$ were cut from the abaxial side of each claw in such a way that the sample included the horn of the abaxial wall, pedal bone, and the interposed corium. The samples were kept on ice until being mounted in a large deformation rheometer with an extension testing frame, fixed by the horn and the pedal bone, and loaded to failure. During deformation force and displacement data were recorded, from which corresponding stress and strain were calculated. Young's modulus (a measure of tissue elasticity or stiffness) and a measure of physiological support (PS; force needed to displace the sample $1 \mathrm{~mm}$ ) were calculated from the data. The response variables, Young's modulus and PS, were analyzed separately by a mixed model. The explanatory variables were treatment (frozen or nonfrozen), limb (front or back), claw (medial or lateral), position of the sample (dorsal or palmarplantar), and group (Angus or Holstein). Interactions
\end{abstract}

Received July 1, 2013.

Accepted February 5, 2014.

${ }^{1}$ Corresponding author: ad@sund.ku.dk between group and treatment and between limb, claw, and sample position were included in the model. Cow identity was included as a random effect. Model reduction was performed by stepwise backward elimination, until all remaining terms were significant at the $5 \%$ level or less. Freezing had no effect on the elasticity of the suspensory apparatus or on PS. However, PS was affected by limb (hind legs had higher PS values than front) and the position of the sample (palmar-plantar samples had higher PS values than dorsal). The Angus group had higher PS values than the Holstein group, but the groups differed in age, parity, body weight, lactation, housing, and management, as well as in breed; therefore, further studies are needed to investigate these effects. The results indicate that mechanical testing of bovine claw suspensory tissue can be performed on specimens that have been frozen, thus aiding research in the mechanical aspect of bovine lameness and claw lesions.

Key words: biomechanics, claw suspensory tissue, Young's modulus, bovine lameness

\section{Technical Note}

Lameness has a large effect on economy (Esslemont and Kossaibati, 1997; Vatandoost et al., 2009) and animal welfare in dairy production (Esslemont and Kossaibati, 1997). However, because the pathogenesis behind development of lameness is not completely understood, methods for treatment and prevention are still not optimal. Many theories have been put forth; one well-established supposition proposes that a central element in the pathogenesis is the weakening and subsequent failure of the tissue supporting the third phalanx within the claw capsule. This may induce trauma in the internal tissue in the claw leading to necrosis and lameness (Ossent and Lischer, 1996, 1998; Pollitt, 2010).

If frozen storage of claws before mechanical testing were possible, more precise epidemiological investigations of possible relationships between herd factors, occurrence of lameness, and claw tissue strength would be 
possible. One can hypothesize that freezing could have a detrimental effect on the suspensory tissue, which would render any results unreliable, as the suspensory tissue is not a homogenous tissue. The bearing force is created by a dense matrix of corium connective tissue that connects the dermal-epidermal junction to the parietal surface of the distal phalanx and thus suspends the distal phalanx from the inner wall of the claw capsule (Pollitt, 2010). The effect of freezing on ligaments, which is composed of connective tissue, has been investigated with varying results. Dorlot et al. (1980) found that frozen storage of canine anterior cruciate ligaments resulted in decreased elasticity, whereas Matthews and Ellis (1968) found the opposite to be true in a study on cat extensor communis and lateralis tendons. Viidik and Lewin (1966), Van Brocklin and Ellis (1965), and Abreu et al. (2009) found no change in the elastic properties of rabbit anterior cruciate ligaments, human extensor digitorum tendons, and rat tail tendons, respectively, after freezing. Tarlton and Webster (2000) reported that storage at $-20^{\circ} \mathrm{C}$ had no effect on the biomechanical strength of the suspensory tissue in bovine claws, but the details of this study have not been published. Thus, the consequences of freezing are not clear and, therefore, the current study aimed to investigate the effect of frozen storage on biomechanical properties of the suspensory tissue in the bovine claw.

\section{Animals}

Limbs from 3 Danish Holstein dairy cows and 6 nonpregnant Angus heifers collected from abattoirs were used in our study. The 3 Holsteins originated from 3 different herds and their background was unknown. The 6 Angus heifers originated from the same herd, were 18 mo old, and had been raised entirely on pasture.

\section{Tissue Samples}

Limbs, cut below the hock or carpal joint, were collected after slaughter. Limbs were assigned to 2 treatments (frozen and nonfrozen) in such a way, that each animal's frozen limb had a corresponding nonfrozen leg (i.e., frozen left front, nonfrozen right front and frozen right hind, nonfrozen left hind). Within $2 \mathrm{~h}$ of slaughter, the nonfrozen limbs were processed as described herein. The frozen limbs were stored at $-18^{\circ} \mathrm{C}$ for a week before processing.

Tissue samples were obtained by use of a band saw according to Figure 1. The frozen claws were cut directly from the freezer. This produced 4 samples per foot: a palmar-plantar and a dorsal sample from the medial claw and the same from the lateral claw. The dorsal samples were marked and the set of dorsal and palmarplantar samples were stored in a plastic container with tap water-soaked cotton wool and then placed on ice until mechanical testing.

\section{Mechanical Testing}

The dimensions of the samples were measured using digital calipers (Limit, Teng Tools International, Alingås, Sweden) and entered into Excel, calculating the area and volume of the lamellar tissue and corium. Each sample was mounted in an Instron 5564 mechanical testing frame, with a 500-N load cell (Instron, High Wycombe, UK) fixed by the horn and the bone. The frame was loaded to failure at a constant extension rate of $2.0 \mathrm{~mm}$ per second, producing data on the uniaxial extension $(\mathrm{mm})$ and force $(\mathrm{N})$. Most samples did not reach the point of failure, as the testing frame's maximum load was $500 \mathrm{~N}$. No more than $2 \mathrm{~h}$ passed between cutting the samples until the mechanical testing commenced.

To compare samples of different sizes, the data was converted to standardized values. The displacement (mm) during extension was converted into Hencky strain, which is a measure of the total height upon extension of a sample $\left(\mathbf{H}_{\mathbf{t}}\right)$ relative to the initial height of the sample $\left(\mathbf{H}_{\mathbf{0}}\right)$ :

$$
\text { Hencky strain }=\ln \left(\mathrm{H}_{\mathrm{t}} / \mathrm{H}_{0}\right) .
$$

The force $\left(F_{t}\right)$, in newtons, during extension was converted to stress $\left(\mathrm{Pa}=\mathrm{N} / \mathrm{m}^{2}\right)$, and thus standardized relative to the cross sectional area of the sample $\left(\mathrm{A}_{0}\right)$ and for the change in height during the testing process $\left(\mathrm{H}_{\mathrm{t}} / \mathrm{H}_{0}\right)$ :

$$
\text { Stress }=\left(\mathrm{F}_{\mathrm{t}} / \mathrm{A}_{0}\right) \times\left(\mathrm{H}_{\mathrm{t}} / \mathrm{H}_{0}\right) .
$$

The data were plotted with the stress against strain, where the slope is the elastic modulus, also called Young's modulus, and thus representing the tissue's proportionality constant between stress and strain (Figure 2).

To assess a measure of the claw tissue's resistance to physiologic stress levels, the samples' physiological support level (PS), here defined as the stress needed to displace the horn $1 \mathrm{~mm}$ in relation to the bone, was recorded (Danscher et al., 2010). Measures of physiological support have been used by Danscher et al. (2010) and Tarlton et al. (2002) as a measure of the tissues' strength or elasticity. The PS uses absolute measurements that have not been standardized in relation to the sample height as it changes during the extension, 


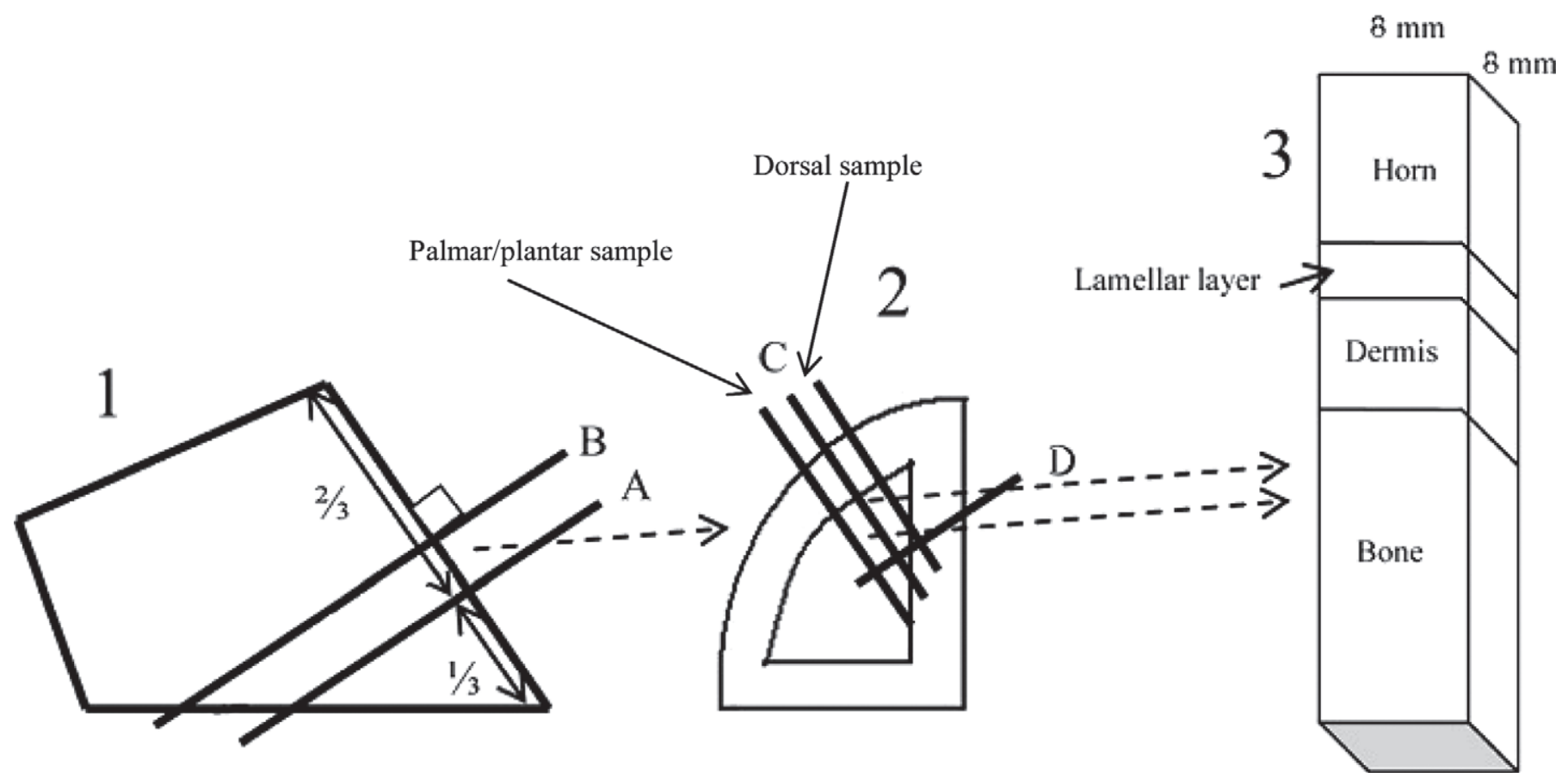

Figure 1. Sampling of claw tissue made by 2 transverse cuts (A and B) perpendicular to the dorsal claw wall (1). Cut A was placed onethird of the distance from the toe to the coronary band and cut B was placed $8 \mathrm{~mm}$ above cut A. This resulted in a slice of the claw (2) into which 3 parallel cuts $(\mathrm{C}), 8 \mathrm{~mm}$ apart, were made perpendicular to the most level surface of the abaxial wall. A final cut through the bone (D) separated the 2 rods into 2 samples (3) containing horn, lamellar layer, dermis, and bone. These samples were used in the mechanical testing (modified from Danscher et al., 2010).

but for the sake of comparison with Danscher et al. (2010), PS was also included in this study.

\section{Statistics}

The model was validated graphically, and square root transformation of the data was performed before analysis. The response variables, Young's modulus and PS, were analyzed separately by a mixed effects model (Proc Mixed with Satterthwaithe's approximated Ftests in SAS 9.1; SAS Institute Inc., Cary, NC). The explanatory variables were treatment (frozen or nonfrozen), limb (front or back), claw (medial or lateral), the position of the sample (dorsal or palmar-plantar), and group (Angus or Holstein). Interactions between group and treatment were included in the full model as well as all interactions between leg, claw, and sample position. Cow identity was included as random effect. Model reduction was performed by stepwise backward elimination, removing the least significant variable or interaction until all remaining terms were significant at the $5 \%$ level or less. The least squares means were transformed back to original scale and compared.

\section{Results}

Freezing had no statistically significant effect on Young's modulus or PS. Furthermore, Young's modu- lus was not statistically significantly affected by any of the explanatory effects in the model. Physiological support level was found to be affected by limb, position of the sample, and group (Table 1). Hind legs had a significantly higher PS level than front legs. Samples in the palmar-plantar position had a significantly higher PS value than samples in the dorsal position. The Angus group had a significantly higher PS value than the Holstein group.

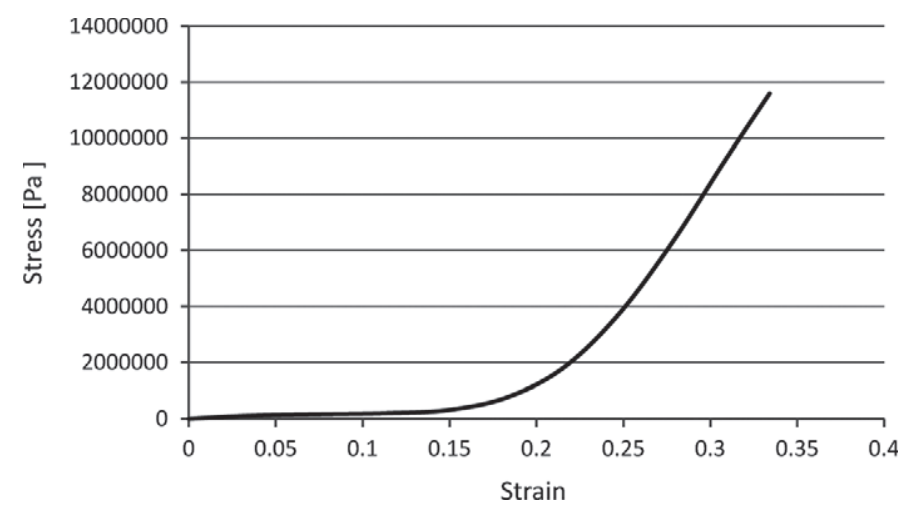

Figure 2. Example of a graph plotting stress against strain. To calculate Young's modulus, the most linear part in the vertical section of the graph (in this case strain is 0.25 to 0.30 ) was selected and the slope of this line was calculated. 
Table 1. Effect on physiological support level of the suspensory tissue of the bovine claw expressed as differences between least squared means from the mixed effects model transformed back to the original scale

\begin{tabular}{llcc}
\hline Effect & Calculation & $\begin{array}{c}\text { Difference } \\
\left(\mathrm{N} / \mathrm{cm}^{2}\right)\end{array}$ & $P$-value \\
\hline Limb & Hind-front & 17 & 0.021 \\
Position & Palmar/plantar-dorsal & 18 & 0.0075 \\
Group & Angus-Holstein & 96 & 0.0008 \\
\hline
\end{tabular}

\section{Discussion}

The overall purpose of our study was to test if research into bovine lameness and claw lesions could be facilitated by freezing specimens, thus aiding the collection and storage of these specimens. We found no discernible effect of freezing on either elasticity or PS. We chose a freezing temperature $\left(-18^{\circ} \mathrm{C}\right)$ any generic commercial freezer would be able to replicate. Paul et al. (1997) state that rapid freezing at $-80^{\circ} \mathrm{C}$ decreases the detrimental effects of freezing; but, as limbs are large specimens, an impractical and large amount of dry ice or liquid nitrogen will have to be used. One of the advantages of freezing at very low temperatures is the instant encompassing suspension. Large specimens, such as a cow limb, would, despite very low temperatures, freeze at an uneven rate, as it would take varying time for the tissues to cool. Freezing at $-20^{\circ} \mathrm{C}$ has its drawbacks as well. The water crystals that form, as well as the destructive forces of shifting osmotic pressure within the intercellular and extracellular compartments, can cause damage to cellular structures (Quirinia and Viidik, 1991; Noakes et al., 2001). As we only tested the effect of freezing on the biomechanical properties of the suspensory apparatus, we cannot conclude anything regarding the effect on the cellular structures. This is also a concern in relation to the fact that future studies most likely will include both healthy and lame cows with a high proportion of pathological changes in the claws. How this affects the properties when exposed to frozen storage needs to be studied.

The hind limbs were found to have a higher PS level than the front limbs, which corresponds with the findings of Danscher et al. (2010). Maierl et al. (2002), conversely, found no difference when testing their strength. The cow carries a slight proportion more of its weight on the front legs (Chapinal et al., 2009), but the hind legs suspensory apparatus may have to be stronger to propel the body forward, as suggested earlier (Danscher et al. 2010).

The current study resulted in higher PS values for the palmar-plantar sample than for the dorsal sample. This supported the findings of Maierl et al. (2002) that the tensile strength is highest on the palmar-plantar side and decreases dorsally. Danscher et al. (2010) found that dorsal samples had a higher PS than palmarplantar samples, which might be explained by the large blood vessel observed in some of the palmar-plantar samples. To avoid this problem in the present study, larger samples $(8 \times 8 \mathrm{~mm})$ were collected, as opposed to the $3-\times 3$-mm samples in the study of Danscher et al. (2010). Differences in the tensile strength of the suspensory apparatus within different locations in the claw could be explained by the different shapes and load bearings of hind, front, medial, or lateral claws (Maierl et al., 2002).

The Angus group had higher PS values than the Holstein group. However, the groups in our study differed not only in breed, but also in age, BW, parity, lactation stage, housing, and management. Thus, these factors are all confounded with each other and further studies will be needed to investigate these effects. Danscher et al. (2010) found that heifers raised in a freestall had higher PS values than heifers raised in tiestalls, indicating that housing has an effect, as Knott et al. (2007) also concluded. Knott et al. (2007) and Tarlton et al. (2002) have also shown that claw strength weakens in the weeks before parturition.

Physiological support level was affected by several of the studied factors, whereas Young's modulus was not. This might indicate that PS is a slightly more sensitive measure of changes in claw tissue strength. However, PS is also less standardized, and thus less accurate and reliable than Young's modulus. Young's modulus is calculated as the slope of the stable linear section of the stress-strain plot where the connective tissue is bearing full load, whereas PS represents the strength of the suspensory tissue in the first millimeter of movement. It may be speculated that differences in anatomical location or changes in animal or herd factors have more effect on the strength in the first millimeter of movement (PS) than on the overall elasticity of the tissue (Young's modulus).

Other studies (Tarlton and Webster, 2000; Maierl et al., 2002; Tarlton et al., 2002; Knott et al., 2007; Danscher et al., 2010) have evaluated the maximum support of the suspensory apparatus by stretching the samples to their breaking point. The maximum load of the testing frame used in the current study was $500 \mathrm{~N}$ and $62 \%$ of the samples did not break. The maximum support was not necessary for calculation of Young's modulus, as it is calculated in a strain area before and not including the maximum strain. It can be argued that maximum strain is less interesting for the physiological function of the tissue, as this level of strain almost never occurs in a live animal.

The suspensory apparatus does not attach to the distant phalanx and the inner claw wall at right angles. 
It slopes downward from the inner claw wall attaching at an angle to the distal phalanx (Pollitt, 2010). This is applicable to horses, and we assume, though it has not been scientifically proven, that this applies to cattle as well. In the current study, samples were cut perpendicular to the dorsal claw wall, thus the test force applied did not correspond with the force direction the suspensory apparatus would experience in a standing animal. This was done to standardize the sampling, as it provided easy landmarks for cutting and ensured that the sample did not contain coronary dermis. This was feasible, as the study was set up to detect the effect of freezing and not to determine the physiologic properties of the suspensory apparatus.

In conclusion, frozen storage at $-18^{\circ} \mathrm{C}$ did not have any discernible effect on the elasticity or the physical support of the suspensory apparatus. Our results indicate that mechanical testing of bovine claw suspensory tissue can be performed on specimens that have been frozen. This finding could prove useful for future research on the mechanical aspect of bovine lameness.

\section{ACKNOWLEDGMENTS}

This study was made possible by the Sund Klov (Healthy Claw) project, which is supported by the Danish Milk Levy Fund (Viby, Denmark).

\section{REFERENCES}

Abreu, E. L., M. P. Palmer, and M. M. Murray. 2009. Storage conditions do not have detrimental effect on allograft collagen or scaffold performance. Cell Tissue Bank. 10:333-340.

Chapinal, N., A. M. de Passille, and J. Rushen. 2009. Weight distribution and gait in dairy cattle are affected by milking and late pregnancy. J. Dairy Sci. 92:581-588.

Danscher, A. M., T. H. Toelboell, and O. Wattle. 2010. Biomechanics and histology of bovine claw suspensory tissue in early acute laminitis. J. Dairy Sci. 93:53-62.

Dorlot, J. M., M. Aitbasidi, G. M. Tremblay, and G. Drouin. 1980 Load elongation behavior of the canine anterior cruciate ligament. J. Biomech. Eng. 102:190-193.
Esslemont, R. J., and M. A. Kossaibati. 1997. Culling in 50 dairy herds in England. Vet. Rec. 140:36-39.

Knott, L., J. F. Tarlton, H. Craft, and A. J. F. Webster. 2007. Effects of housing, parturition and diet change on the biochemistry and biomechanics of the support structures of the hoof of dairy heifers. Vet. J. 174:277-287.

Maierl, J., R. Bohmisch, M. Dickomeit, and H. G. Liebich. 2002. A method of biomechanical testing the suspensory apparatus of the third phalanx in cattle: A technical note. Anat. Histol. Embryol. 31:321-325.

Matthews, L. S., and D. Ellis. 1968. Viscoelastic properties of cat tendon: Effects of time after death and preservation by freezing. J. Biomech. 1:65-71.

Noakes, D. E., T. J. Parkinson, and G. C. W. England. 2001. Artificial insemination. Pages 755-758 in Arthur's Veterinary Reproduction and Obstetrics. 8th ed. Saunders/Elsevier, Philadelphia, PA.

Ossent, P., and C. Lischer. 1996. The pathology of digital disease and theories on the pathogenesis of bovine laminitis. Ir. Vet. J. 49:485-487.

Ossent, P., and C. Lischer. 1998. Bovine laminitis: The lesions and their pathogenesis. In Pract. 20:415.

Paul, R. G., J. F. Tarlton, P. P. Purslow, T. J. Sims, P. Watkins, F. Marshall, M. J. Ferguson, and A. J. Bailey. 1997. Biomechanical and biochemical study of a standardized wound healing model. Int. J. Biochem. Cell Biol. 29:211-220.

Pollitt, C. C. 2010. The anatomy and physiology of the suspensory apparatus of the distal phalanx. Vet. Clin. North Am. Equine Pract. 26:29-49.

Quirinia, A., and A. Viidik. 1991. Freezing for postmortal storage influences the biomechanical properties of linear skin wounds. J. Biomech. 24:819-823.

Tarlton, J. F., D. E. Holah, K. M. Evans, S. Jones, G. R. Pearson, and A. J. F. Webster. 2002. Biomechanical and histopathological changes in the support structures of bovine hooves around the time of first calving. Vet. J. 163:196-204.

Tarlton, J. F., and A. J. F. Webster. 2000. Biochemical, biomechanical and histological analyses of failure of supportive structures in cattle hooves. Page 126 in Proc. Br. Soc. Anim. Sci. Br. Soc. Anim. Sci., Midlothian, UK.

Van Brocklin, J. D., and D. Ellis. 1965. A study of the mechanical behaviour of toe extensor tendons under applied stress. Arch. Phys. Med. Rehabil. 47:369-373.

Vatandoost, M., M. A. Norouzian, and M. Nosrati. 2009. Estimation of milk yield and economic loss resulting to laminitis in Holstein cow: A case study. J. Anim. Vet. Adv. 8:880-882.

Viidik, A., and T. Lewin. 1966. Changes in tensile strength characteristics and histology of rabbit ligaments induced by different modes of post mortal storage. Acta Orthop. Scand. 37:141-155. 